\title{
Surgical Risk and Pathological Results of Emergency Resection in the Treatment of Acutely Obstructing Colorectal Cancers: A Retrospective Cohort Study
}

\author{
Giovanni Domenico Tebala ${ }^{1,2}$, Andrea Mingoli $^{3}$, Andrea Natili ${ }^{1,3,4}$, Abdul Qayyum Khan ${ }^{1}$, Gioia Brachini ${ }^{3}$ \\ ${ }^{1}$ Colorectal Team, Noble's Hospital, Isle of Man, British Isles; ${ }^{2}$ Surgical Emergency Unit, John Radcliffe Hospital, Oxford University Hospitals \\ NHS Foundation Trust, Oxford, UK; ${ }^{3}$ Emergency Surgery Unit, “P. Valdoni” Department of Surgery, Umberto I University Hospital, Rome, \\ Italy; ${ }^{4}$ General and Transplantation Surgery Unit, S. Salvatore Regional Hospital, L’Aquila, Italy
}

Purpose: The treatment of acutely obstructing colorectal cancers is still a matter of debate. The prevailing opinion is that an immediate resection should be performed whenever possible. This study sought to determine whether immediate resection is safe and oncologically valid.

Methods: We completed a retrospective 2-center cohort study using the medical records of patients admitted for acutely obstructing colorectal cancer under the care of the Colorectal Team, Noble's Hospital, Isle of Man, and the Emergency Surgery Unit, Umberto I University Hospital, Rome, from March 2013 to May 2017. The primary endpoints were 90-day mortality and morbidity, reoperation rate, and length of stay. The secondary endpoints were status of margins, number of lymph nodes retrieved, and the rate of adequate nodal harvest.

Results: Sixty-three patients were retrospectively enrolled in the study. Mortality was associated with age $>80$ years and Dukes B tumors. The length of hospital stay was shorter in patients who had their resection less than 24 hours from their admission, in those who had laparoscopic resection and in those with distal tumors. The number of lymph nodes retrieved and rate of $\mathrm{R} 0$ resections were similar to those reported in elective colorectal surgery and were greater in laparoscopic resections and in patients operated on within 24 hours, respectively.

Conclusion: Immediate resection is a safe and reliable option in patients with acutely obstructing colorectal cancer.

Keywords: Colorectal surgery; Intestinal obstruction; Colonic neoplasms

\section{INTRODUCTION}

Colorectal cancer is one of the most common malignant diseases, with an incidence of about 70 new cases per 100,000 per year in the Western world $[1,2]$. About $20 \%$ of those cases present as

Received: Jan 2, 2019 - Revised: Mar 9, 2019 - Accepted: Mar 10, 2019 Correspondence to: Giovanni D. Tebala, M.D., FRCS, FACS

Surgical Emergency Unit, John Radcliffe Hospital, Oxford University Hospitals NHS Foundation Trust, Headley Way, Headington, Oxford OX3 9DU, UK

Tel: +447555349834

E-mail: giovanni.tebala@ouh.nhs.uk

ORCID: https://orcid.org/0000-0001-7152-4096

(C) 2020 The Korean Society of Coloproctology

This is an open-access article distributed under the terms of the Creative Commons Attribution NonCommercial License (https://creativecommons.org/licenses/by-nc/4.0) which permits unrestricted noncommercial use, distribution, and reproduction in any medium, provided the original work is properly cited. emergencies, most frequently due to bowel obstruction [3]. On average, these patients have more aggressive cancers and usually have a worse prognosis with respect to elective cases $[4,5]$.

A high percentage of these cases are non-operable at presentation, due to advanced disease or very poor general conditions [5].

The treatment of colorectal cancer presenting with bowel obstruction has not yet been standardized. The prevailing opinion is to perform an emergency resection, with or without immediate anastomosis, but the choice of the best treatment is usually determined by the on-call surgeon, who may not be a subspecialist colorectal surgeon, and with the patient, whose ability of retain and use the information he/she received for a sound informed consent can be impaired in the emergency setting. It is therefore important that the surgeon has a full knowledge of the risks and benefits associated with the decision to perform an immediate resection. 
The aim of this study was to evaluate the efficacy and safety of immediate resection in patients with colorectal cancer presenting acutely with large bowel obstruction.

\section{METHODS}

The records of all patients admitted as emergencies for bowel obstruction due to colorectal cancer between March 2013 and May 2017 have been reviewed. The clinical records of patients who underwent immediate resection were entered into an electronic database and analyzed with IBM SPSS Statistics ver. 20.0 (IBM Corp., Armonk, NY, USA). Cases with associated bowel perforation were excluded, as were those who had received any kind of damage-control procedure prior to resection (i.e., stoma or stent).

To reduce the risk that the results were biased by the use of a single center and social environment, we decided to pool case series data from 2 different hospitals, namely the Colorectal Team of the Noble's Hospital, Isle of Man (British Isles) and of the Emergency Surgery Unit of the Umberto I University Hospital in Rome (Italy).

Obstruction was diagnosed in all cases using abdominal plain films and/or computed tomography (CT) scan, following assessment against clinical diagnostic criteria, namely bowel not opened for at least 3 days, no passage of wind in the last 2 days, abdominal distension, pain and/or fecal vomiting, obstructive bowel sounds, and air-fluid level and proximal distension at plain abdominal film and/or CT scan.

No tissue diagnosis was available before surgery, as none of the patients had preoperative colonoscopy and the indication for surgery was bowel obstruction irrespective of diagnosis.

Immediate resection has been defined as a formal surgical resection of obstructing cancer with no previous damage-control procedure.

Data related to the patient (age, sex, American Society of Anesthesiologists [ASA] physical status classification score), to the tumor (stage, localization), and to the treatment (timing of admission, timing of resection, kind of resection, stoma) were considered. The primary study endpoints were 90-day mortality and morbidity (Clavien-Dindo classification > II) [6], rate of unplanned reoperations and length of stay (LOS). The secondary endpoints were status of margins, number of lymph nodes retrieved, and rate of adequate nodal harvesting. The LOS was calculated after excluding the patients who passed away after the operation. Mortality, morbidity, rate of unplanned reoperations, and LOS were considered to be indicators of the degree of safety, whereas the status of margins and nodal harvesting adequacy were considered indicators of efficacy.

Data for normally distributed continuous variables were described using the mean \pm standard deviation and their association with the prognostic factors analyzed with Student $\mathrm{t}$-test. Data for nonnormally distributed continuous variables were described using the median and range and were compared using the Mann-
Whitney U-test. Data for nominal and categorical variables were described as the fraction and/or percentage and have been compared with Pearson chi-square test.

Independent risk factors were identified by multivariate analyses using stepwise logistic regression for nominal variables and stepwise linear regression for continuous variables. All investigated factors were considered in the multivariate analyses irrespective of the results of univariate analyses, under the assumption that any lack of association of a variable with a specific outcome in the univariate analyses could be potentially due to confounding factors. Reported P-values were 2-tailed. P-values $<0.05$ were considered to be statistically significant.

The retrospective nature of this study made formal ethical approval unnecessary. However, the Ethical Committees of both the Noble's Hospital and the Umberto I Hospital have been informed

Table 1. The number of operations performed (laparoscopic resections), complications of Clavien-Dindo > II, and reoperations

\begin{tabular}{|c|c|}
\hline Variable & No. of operations (laparoscopic resections) \\
\hline \multicolumn{2}{|l|}{ Operations } \\
\hline Right colectomy & $23(4)$ \\
\hline Extended right colectomy & 7 \\
\hline Left colectomy & $16(4)$ \\
\hline Hartmann's & 6 \\
\hline Sigmoid resection & $1(1)$ \\
\hline Anterior resection & 1 \\
\hline Total/subtotal colectomy & 9 \\
\hline \multicolumn{2}{|l|}{ Ostomies } \\
\hline No stoma & 45 \\
\hline Derivative stoma & 7 \\
\hline Terminal stoma & 11 \\
\hline \multicolumn{2}{|l|}{ Complications } \\
\hline Leak & 8 \\
\hline Anastomotic bleeding & 1 \\
\hline Bowel obstruction & 1 \\
\hline Septic shock & 1 \\
\hline Eventration & 1 \\
\hline Stroke & 1 \\
\hline DVT/PE & 1 \\
\hline \multicolumn{2}{|l|}{ Reoperations } \\
\hline Laparotomy and drainage & 3 \\
\hline lleostomy & 3 \\
\hline Meckel diverticulectomy & 1 \\
\hline Reresection/anastomosis & 1 \\
\hline Abdominal wall closure & 1 \\
\hline
\end{tabular}

DVT, deep vein thrombosis; PE, pulmonary embolism. 
and they both considered ethical approval was not necessary on the following bases: (1) the data were completely anonymized, (2) the data were collected as part of the normal treatment for the patients and were subsequently analyzed within an audit aimed at improving our quality of care, (3) patients were treated according to national and international guidelines, and (4) no experimental or new treatments/protocols are included in this report. The patients' data confidentiality was not breached as all data were collected and analyzed in an anonymized manner. Informed consent to treatment was obtained from all individual participants included in the study. However, as all data were anonymized and no individual patient data were reported, consent for publication was considered unnecessary.

This article has been drafted following the PROCESS (Preferred Reporting Of CasE Series in Surgery) guidelines [7].

\section{RESULTS}

During the study period, 63 patients underwent immediate resection for obstructing colorectal cancer. There were 32 female and 31 male patients, aged $73.2 \pm 11.4$ years (median, 73 years; range, 39-97 years).

Table 1 presents the operations performed along with the complications and reoperations.

Twenty-one patients (33.3\%) were admitted within 24 hours of the onset of their symptoms and $47(74.6 \%)$ were resected within 24 hours of their admission. Forty-five patients (71.4\%) did not have a stoma, whereas 7 patients $(11.1 \%)$ had a derivative stoma after anastomosis and 11 patients (17.5\%) had a terminal stoma without anastomosis.

The distribution of prognostic factors and results of their comparisons are reported in Tables 2 to 5. Only the most significant results are highlighted in the narrative below.

Postoperative 90-day mortality was greater in women than in men, but this difference did not reach statistical significance. Mortality was significantly greater in elderly patients, in patients with multiple severe comorbidities and in those with Dukes B tumor with respect to those with Dukes C and D tumors.

Perioperative 90-day morbidity was higher in Dukes B and D patients and in those operated on by open surgery.

Unplanned reoperations were necessary in $14.3 \%$ of patients. The risk of reoperation was greater in patients who had a derivative stoma. The statistical analyses indicated than reoperation was also related to Dukes tumor stage, as no Dukes $\mathrm{C}$ patients required reoperation. Dukes $\mathrm{C}$ patients also who had the lowest morbidity.

The LOS was a numeric variable with non-normal distribution. The median LOS was 10 days, and the range was between 1 and 122 days. In univariate analyses, LOS was influenced only by the timing of resection and by the kind of approach, being shorter in those patients who had their resection within 24 hours of admission and who had laparoscopic resection.

The number of lymph nodes retrieved and analyzed was distributed normally. The average number of nodes was greater in younger and healthier patients as compared to elderly and highASA patients. There was also a nonsignificant trend of laparo-

Table 2. Analysis of the factors pertaining to the patients

\begin{tabular}{|c|c|c|c|c|c|c|c|c|}
\hline Variable & Total & 90-Day mortality & 90-Day morbidity & Reoperation & LOS (day) & No. of LNs & Adequate of No. of LNs & Ro \\
\hline Total & 63 & $9(14.3)$ & $16(25.4)$ & $9(14.3)$ & $10(1-122)$ & $17.9 \pm 9.8$ & $46(73.0)$ & $54(85.7)$ \\
\hline \multicolumn{9}{|l|}{ Sex } \\
\hline Female & $32(49.2)$ & $7(21.9)$ & $9(28.1)$ & $5(16.1)$ & $9(1-122)$ & $18.1 \pm 7.7$ & $22(68.8)$ & $28(90.3)$ \\
\hline P-value & & 0.080 & 0.613 & 0.681 & 0.404 & 0.826 & 0.438 & 0.304 \\
\hline$>80$ & $18(28.6)$ & $6(33.3)$ & $7(38.9)$ & $3(16.7)$ & $12.5(1-44)$ & $13.9 \pm 5.1$ & $12(66.7)$ & $18(100)$ \\
\hline P-value & & 0.006 & 0.120 & 0.733 & 0.518 & 0.059 & 0.473 & 0.04 \\
\hline \multicolumn{9}{|l|}{ ASA } \\
\hline 1 & $1(1.6)$ & 0 & 0 & 0 & 6 & 64 & $1(100)$ & 0 \\
\hline P-value & & 0.006 & 0.291 & 0.789 & 0.223 & 0.000 & 0.141 & 0.051 \\
\hline
\end{tabular}

Values are presented as number (\%), median (range), or mean \pm standard deviation.

LOS, length of stay; LN, lymph node; ASA, American Society of Anesthesiologists physical status classification. 
Table 3. Analysis of the factors pertaining to the tumor

\begin{tabular}{|c|c|c|c|c|c|c|c|c|}
\hline Variable & Total & 90-Day mortality & 90-Day morbidity & Reoperation & LOS (day) & No. of LNs & Adequate of No. of $\mathrm{LNs}$ & Ro \\
\hline \multicolumn{9}{|l|}{ Dukes } \\
\hline B & $28(44.4)$ & $7(25.0)$ & 11(39.3) & $7(25.0)$ & $13(1-64)$ & $16.3 \pm 8.6$ & $17(60.7)$ & $26(92.9)$ \\
\hline C & $24(38.1)$ & $2(8.3)$ & $2(8.3)$ & $0(0)$ & $10(1-122)$ & $21.2 \pm 11.1$ & $22(91.7)$ & $20(83.3)$ \\
\hline D & $11(17.5)$ & $0(0)$ & $3(27.3)$ & $2(18.2)$ & $10(6-53)$ & $14.4 \pm 8.7$ & 7 (63.6) & $8(72.7)$ \\
\hline P-value & & 0.076 & 0.038 & 0.034 & 0.393 & 0.104 & 0.032 & 0.247 \\
\hline \multicolumn{9}{|l|}{ Tumor } \\
\hline Prox & $28(44.4)$ & $3(10.7)$ & $6(21.4)$ & $4(14.3)$ & $10(3-53)$ & $19.5 \pm 11.9$ & $22(78.6)$ & $21(75.0)$ \\
\hline Distal & $30(47.6)$ & $6(20.0)$ & $7(23.3)$ & $3(10.0)$ & $10(1-122)$ & $17.5 \pm 7.5$ & $22(73.3)$ & $28(93.3)$ \\
\hline Rectum & $5(7.9)$ & $0(0)$ & $3(60.0)$ & $2(40.0)$ & $17(7-64)$ & $10.6 \pm 7.0$ & $2(40.0)$ & $5(100)$ \\
\hline P-value & & 0.382 & 0.177 & 0.207 & 0.266 & 0.174 & 0.201 & 0.087 \\
\hline
\end{tabular}

Values are presented as number (\%), median (range), or mean \pm standard deviation.

LOS, length of stay; LN, lymph node.

Table 4. Analysis of the factors pertaining to treatment

\begin{tabular}{|c|c|c|c|c|c|c|c|c|}
\hline Variable & Total & 90-Day mortality & 90-Day morbidity & Reoperation & LOS (day) & No. of LNs & Adequate of No. of LNs & Ro \\
\hline \multicolumn{9}{|c|}{ Timing of admission } \\
\hline$<24 \mathrm{hr}$ & 21 (33.3) & $4(19.0)$ & $4(19.0)$ & $3(14.3)$ & $10(1-122)$ & $17.8 \pm 6.4$ & $18(85.7)$ & $16(76.2)$ \\
\hline$\geq 24 \mathrm{hr}$ & $42(66.7)$ & $5(11.9)$ & $12(28.6)$ & $6(14.3)$ & $10(3-64)$ & $17.8 \pm 11.4$ & $28(66.7)$ & $38(90.5)$ \\
\hline P-value & & 0.445 & 0.413 & 1.000 & 0.866 & 0.982 & 0.108 & 0.127 \\
\hline \multicolumn{9}{|c|}{ Timing of resection } \\
\hline$<24 \mathrm{hr}$ & $47(74.6)$ & $8(17.0)$ & $13(27.7)$ & $2(12.5)$ & $9(1-64)$ & $18.2 \pm 10.9$ & $32(68.1)$ & $43(91.5)$ \\
\hline$\geq 24 \mathrm{hr}$ & $16(25.4)$ & $1(6.3)$ & $3(18.8)$ & $7(14.9)$ & $14(1-122)$ & $16.9 \pm 5.8$ & $14(87.5)$ & $11(68.8)$ \\
\hline P-value & & 0.288 & 0.479 & 0.813 & 0.006 & 0.659 & 0.131 & 0.025 \\
\hline \multicolumn{9}{|c|}{ Weekend admission } \\
\hline Yes & $22(34.9)$ & $3(13.6)$ & $4(18.2)$ & $2(9.1)$ & $13(7-122)$ & $17.7 \pm 9.4$ & 15 (68.2) & $20(90.9)$ \\
\hline No & $41(65.1)$ & $6(14.6)$ & $12(29.3)$ & $7(17.1)$ & $9(1-53)$ & $17.9 \pm 10.2$ & 31 (75.6) & 34 (82.9) \\
\hline P-value & & 0.914 & 0.335 & 0.388 & 0.149 & 0.934 & 0.527 & 0.388 \\
\hline \multicolumn{9}{|c|}{ Weekend resection } \\
\hline Yes & $20(31.7)$ & $3(15.0)$ & $5(25.0)$ & $3(15.0)$ & $10(7-122)$ & $17.4 \pm 9.0$ & $15(75.0)$ & $18(90.0)$ \\
\hline No & 43 (68.3) & $6(14.0)$ & $11(25.6)$ & $6(14.0)$ & $10(1-53)$ & $18.0 \pm 10.3$ & 31 (72.1) & $36(83.7)$ \\
\hline P-value & & 0.912 & 0.961 & 0.912 & 0.438 & 0.837 & 0.809 & 0.507 \\
\hline \multicolumn{9}{|l|}{ Approach } \\
\hline Open & $54(85.7)$ & $9(16.7)$ & 16 (29.6) & $9(16.7)$ & $12(1-122)$ & $17.0 \pm 8.3$ & 37 (68.5) & $46(85.2)$ \\
\hline Laparoscopic & $9(14.3)$ & $0(0)$ & $0(0)$ & $0(0)$ & $6(3-15)$ & $22.9 \pm 15.8$ & $9(100)$ & $8(88.9)$ \\
\hline P-value & & 0.186 & 0.059 & 0.186 & 0.002 & 0.096 & 0.049 & 0.769 \\
\hline \multicolumn{9}{|l|}{ Stoma } \\
\hline No & 45 (71.4) & $5(11.1)$ & $9(20.0)$ & $6(13.3)$ & $10(1-122)$ & $19.1 \pm 10.0$ & $36(80.0)$ & 37 (82.2) \\
\hline Derivat & $7(11.1)$ & $1(14.3)$ & $4(57.1)$ & $3(42.9)$ & $11.5(1-64)$ & $12.1 \pm 9.4$ & $3(42.9)$ & $7(100)$ \\
\hline Terminal & $11(17.5)$ & $3(27.3)$ & $3(27.3)$ & $0(0)$ & $13.5(6-27)$ & $16.3 \pm 8.2$ & 7 (63.6) & $10(90.9)$ \\
\hline$P$-value & & 0.390 & 0.109 & 0.038 & 0.578 & 0.201 & 0.089 & 0.395 \\
\hline
\end{tabular}

Values are presented as number (\%), median (range), or mean \pm standard deviation.

LOS, length of stay; LN, lymph node. 
Table 5. Logistic regression analysis

\begin{tabular}{lccccccc}
\hline Variable & 90-Day mortality & 90-Day morbidity & Reoperation & LOS (day) & No. of LNs & Adequate of No. of LNs & R0 \\
\hline Independent factors & $\begin{array}{c}\text { Age }>80 \mathrm{yr} \\
\text { Low Dukes }\end{array}$ & None & None & $\begin{array}{c}\text { Resection }>24 \mathrm{hr} \\
\text { Distal tumor }\end{array}$ & $\begin{array}{c}\text { Low-ASA } \\
\text { Laparoscopic } \\
\text { resection }\end{array}$ & $\begin{array}{c}\text { Low-ASA } \\
\text { Laparoscopic } \\
\text { resection }\end{array}$ & $\begin{array}{c}\text { Resection }<24 \text { hr } \\
\text { Model significance }(P)\end{array}$ \\
\hline
\end{tabular}

LOS, length of stay; LN, lymph node; ASA, American Society of Anesthesiologists physical status classification.

scopic resections yielding a larger number of lymph nodes. However, patients with Dukes C tumors and those who had laparoscopic resection were more likely to have a greater lymph node count.

More than $85 \%$ of resections had clear margins, but this percentage was greater in elderly patients, in those with intermediate ASA physical status classification, and in patients who had emergency resection within 24 hours of admission; the percentage of patients with clear margins was also greater in patients with distal tumors, but this finding was not statistically significant.

Comparison of laparoscopic and open resections confirmed that the former are associated with shorter hospital stay and better nodal clearance.

Patients who were operated on within 24 hours of admission had shorter hospital stays and greater rates of $\mathrm{R} 0$ resections.

In this series, being admitted or operated on during the weekends did not affect the results in any way.

In multivariate analyses (Table 5). mortality was independently associated with age and Dukes stage. The LOS was independently correlated with timing of the resection. In addition, negative circumferential margins status (R0) were correlated with early resection. Perioperative morbidity and the number of lymph nodes were not associated with any of the analyzed factors.

\section{DISCUSSION}

The choice of the treatment in patients with colorectal cancer presenting as emergencies with bowel obstruction has not yet been standardized. The choice of treatment is usually left to the on-call surgeon-who may or may not be a subspecialist colorectal surgeon-and the patient, whose ability to understand, retain and use the information received to give a properly informed consent may be impaired in an emergency situation.

The literature continually provides more and more evidences to be considered in the decision-making process $[8,9]$, but despite some guidelines [10] and-sometimes-common sense seeming to suggest a prudent approach in patients with bowel obstruction due to colorectal cancer, the prevailing opinion is still to perform an emergency resection with or without immediate anastomosis [11]. This has been traditionally considered the best option as it allows treatment of the complications and the primary tumor in one procedure, but it may be associated with a high rate of complications, mostly related to the poor general condition of the pa- tient [12]. A staged approach was therefore proposed, whose philosophy has been borrowed from the treatment of severe trauma, with an initial damage-control procedure, to treat the acute complications and stabilize the patient, followed by an elective resection within days or weeks. The staged approach seems to be associated with better surgical results [13], particularly in high-risk patients $[7,14]$.

It is still a matter for debate what is the best damage-control procedure to be used as a bridge to surgery, but the available literature seems to indicate a preference for stenting over a surgical diversion [15], despite some well-known drawbacks [16, 17].

In current practice, however, there are still quite a few centers that have routinely adopted a staged approach, mostly for left colon obstruction [18].

This 2-center retrospective cohort study was focused on the results of emergency resection, to try to answer the following questions:

(1) Is emergency resection safe?

(2) Is emergency resection oncologically reliable?

The mortality rate in our analyses compared positively with the data reported in the literature [18] and matched that of the UK National Bowel Cancer Audit [19]. It is not surprising that mortality is affected by age and ASA physical status. However, these 2 factors are obviously interconnected, as elderly people are likely to suffer from multiple comorbidities. While there was an evident trend in the univariate analysis (that nonetheless did not reach statistical significance, likely due to the size of the sample), it is much more difficult to explain the results of the multivariate analyses that demonstrated that one of the independent prognostic factors is low Dukes stage. Our impression is that the on-call surgeon might sometimes have been too enthusiastic in recommending emergency resection in high-risk patients with localized tumor/s. Moreover, it could be possible that in patients with an evidently early tumor, the surgeon decided to be a bit more aggressive, thus increasing the risk of mortality and morbidity. In fact, univariate tests confirmed that the morbidity and reoperation rates are also higher in Dukes B patients, although this result has not been confirmed by multivariate analyses. In particular, multivariate analyses failed to identify any single independent causative factor for morbidity and reoperation, thus demonstrating the multifactorial etiology of postoperative complications. It is also possible that morbidity is actually dependent on factors which have not been evaluated in the present study. Prospectively 
collected data would be able to cast some light on the process of surgical morbidity and related causative factors.

The reoperation rate also seemed to be higher in patients who had a resection with immediate anastomosis and protective stoma. This result was evident in the univariate analyses, but disappeared in the multivariate analyses, indicating the high reoperation rate in this group was likely due to other confounding factors, such as a different localization of the tumor (reoperation rate is higher in rectal cancers with respect to colon cancers).

In this study we did not specifically investigate the role of immediate anastomosis, as the risk of leakage is heavily dependent on the localization of the suture. A more strict stratification of cases would have been necessary to evaluate this parameter, but this would have reduced statistical significance due to the small size of the eventual subgroups.

In agreement with the literature [20] and recent guidelines [21], our data may suggest that, when possible, immediate anastomosis without covering stoma is still the safer option, as in our study those patients had the best results in terms of lowest mortality and morbidity, lowest risk of reoperation, shortest stay, and best oncologic outcomes.

Timing of admission and resection did not affect mortality and morbidity, but patients operated on early after admission had a significantly greater rate of negative margins, also confirmed at multivariate analysis. A possible explanation is that delaying the operation beyond 24 hours can allow spread of local inflammation, thus making surgical dissection more difficult. Early operation needs competent and sound decision making, and this can be accomplished only by an experienced member of staff, possibly a consultant. Therefore, senior input is crucial in every phase of the emergency treatment, including triage. Early involvement of the consultant is also the key factor to get good results during the weekend. In our experience, in fact, despite recent warnings [22], admission and/or operation during the weekend did not affect the results of emergency colectomy. It is worth noting that in both surgical units involved in this study, emergency surgeries have almost always been performed by fully trained consultants.

The pathology results in this series are consistent with those reported in the literature $[8,23]$ and not too different from those for elective surgery $[19,24]$. The average number of nodes retrieved and analyzed and rate of adequate lymphadenectomies were greater in low-ASA patients, probably due to a more extensive surgery being performed in patients in better general condition, and in laparoscopic resections, thus confirming once again the reliability of the laparoscopic approach in oncologic surgery of the colon-rectum. ASA physical status classification and laparoscopic resections have also been confirmed as independent factors in multivariate analyses. Unfortunately, this study lacks long-term follow-up, so there are no data regarding survival. However, the number of harvested lymph nodes and status of the surgical margins are considered good surrogate indicators of oncologic outcome, and on the basis of our series, we can therefore confirm the findings of the literature $[6,8,21]$ that immediate resection itself should not affect long-term survival.

Laparoscopic resection is associated with lower morbidity and mortality (difference not statistically significant, but showing a very interesting trend), shorter stay and better nodal clearance (statistically significant) with respect to open surgery. Although many other recent studies confirm that laparoscopic resection can also be feasible and safe in emergency [25], undoubtedly it requires specific advanced laparoscopic skills that are not always part of the skillset of an emergency surgeon. In our series, the number of patients who had laparoscopic resection was quite low, only $14 \%$ of total, thus overlapping the results of the UK National Audit [19], but other authors have reported a much greater rate of laparoscopic emergency resections [26]. This discrepancy may be also due to the different definition of acute obstruction. Whereas in our cases, acute bowel obstruction was strictly defined as (1) no bowel motions in the last 3 days, (2) no passage of wind in the last 2 days, (3) abdominal distension, (4) obstructive bowel sounds, (5) air-fluid level and proximal distension on plain abdominal films and/or CT scans, others may follow less restrictive criteria, such that laparoscopic resection may be easier in patients without massively dilated bowels. Moreover, the patients in our series were operated upon by several surgeons, the majority of whom are not subspecialist laparoscopic colorectal surgeons. We appreciate that the future of colorectal surgery, both in elective and emergency patients, is with the laparoscopic (or robotic) approach, but unfortunately very few training programs have targeted emergency laparoscopic resections, probably due to the false assumption that the usual elective technique can be easily transposed to emergency situations. Unfortunately, this is not the case. Moreover, emergency surgeons are not always specifically skilled in surgery of the lower gastrointestinal tract. A possible solution to this problem is that every newly qualified colorectal surgeon must be able to perform emergency colorectal resections, so that a 24/7 subspecialist rota can be set up at a trust or subregional level (should the trend towards centralization continue) to deal with all the resectable obstructing bowel cancers. Another (probably easier) option would be to reconsider the staged approach for potentially curable colorectal cancers presenting in emergency with bowel obstruction, to treat the complications and stabilize the patients in emergency and then transfer them to a subspecialist colorectal surgeon (possibly laparoscopic) for elective resection, as stated in the UK guidelines [27].

One clear limitation of this study was its retrospective design. As already stated, the selection of treatment strategy in these cases was based on the judgment of the on-call surgeon after considering the general condition of the patients and the diagnostic findings. Due to the peculiar nature of these cases, we feel that a prospective study would be quite difficult to implement and carry on, but the problems and considerations raised in this paper can only be clarified with a proper large-scale randomized controlled trial. In conclusion, our study confirms that immediate resection of 
an acutely obstructing colorectal cancer can be performed safely and effectively. The best results can be obtained when the resection is performed as soon as possible after admission, and possibly by laparoscopy and without a stoma. However, it is advisable to be particularly prudent-and in some cases opt for a staged approach-in elderly patients with multiple comorbidities.

\section{CONFLICT OF INTEREST}

No potential conflict of interest relevant to this article was reported.

\section{REFERENCES}

1. Cancer Research UK. Bowel cancer statistics [Internet]. London: Cancer Research UK [cited 2017 Aug 8]. Available from: http:// www.cancerresearchuk.org/health-professional/cancer-statistics/ statistics-by-cancer-type/bowel-cancer.

2. Associazione Italiana di Oncologia Medica. I numeri del cancro in Italia 2016. Roma: Associazione Italiana di Oncologia Medica; 2016.

3. Gunnarsson H, Jennische K, Forssell S, Granström J, Jestin P, Ekholm A, et al. Heterogeneity of colon cancer patients reported as emergencies. World J Surg 2014;38:1819-26.

4. Hogan J, Samaha G, Burke J, Chang KH, Condon E, Waldron D, et al. Emergency presenting colon cancer is an independent predictor of adverse disease-free survival. Int Surg 2015;100:77-86.

5. Tekkis PP, Kinsman R, Thompson MR, Stamatakis JD; Association of Coloproctology of Great Britain, Ireland. The Association of Coloproctology of Great Britain and Ireland study of large bowel obstruction caused by colorectal cancer. Ann Surg 2004; 240:76-81.

6. Dindo D, Demartines N, Clavien PA. Classification of surgical complications: a new proposal with evaluation in a cohort of 6336 patients and results of a survey. Ann Surg 2004;240:205-13.

7. Agha RA, Fowler AJ, Rajmohan S, Barai I, Orgill DP; PROCESS Group. Preferred reporting of case series in surgery; the PROCESS guidelines. Int J Surg 2016;36(Pt A):319-23.

8. Costa G, Lorenzon L, Massa G, Frezza B, Ferri M, Fransvea P, et al. Emergency surgery for colorectal cancer does not affect nodal harvest comparing elective procedures: a propensity score-matched analysis. Int J Colorectal Dis 2017;32:1453-61.

9. Allievi N, Ceresoli M, Fugazzola P, Montori G, Coccolini F, Ansaloni L. Endoscopic stenting as bridge to surgery versus emergency resection for left-sided malignant colorectal obstruction: an updated meta-analysis. Int J Surg Oncol 2017;2017:2863272.

10. National Comprehensive Cancer Network. NCCN guidelines for patients: colon cancer [Internet]. Fort Wathington (PA): National Comprehensive Cancer Network; 2018 [cited 2017 Aug 18]. Available from: https://www.nccn.org/patients/guidelines/colon/files/ assets/common/downloads/files/colon.pdf.

11. Association of Coloproctology of Great Britain and Ireland.
Guidelines for the management of colorectal Cancer. 3rd ed. 2007 [Internet]. London: Association of Coloproctology of Great Britain and Ireland; 2017 [cited 2017 Aug 17]. Available from: http:// www.acpgbi.org.uk/content/uploads/2007-CC-ManagementGuidelines.pdf.

12. Sjo OH, Larsen S, Lunde OC, Nesbakken A. Short term outcome after emergency and elective surgery for colon cancer. Colorectal Dis 2009;11:733-9.

13. Amelung FJ, Consten ECJ, Siersema PD, Tanis PJ. A populationbased analysis of three treatment modalities for malignant obstruction of the proximal colon: acute resection versus stent or stoma as a bridge to surgery. Ann Surg Oncol 2016;23:3660-8.

14. van Hooft JE, van Halsema EE, Vanbiervliet G, Beets-Tan RG, DeWitt JM, Donnellan F, et al. Self-expandable metal stents for obstructing colonic and extracolonic cancer: European Society of Gastrointestinal Endoscopy (ESGE) Clinical Guideline. Gastrointest Endosc 2014;80:747-61.e1-75.

15. Arezzo A, Balague C, Targarona E, Borghi F, Giraudo G, Ghezzo L, et al. Colonic stenting as a bridge to surgery versus emergency surgery for malignant colonic obstruction: results of a multicentre randomised controlled trial (ESCO trial). Surg Endosc 2017; 31:3297-305.

16. van Hooft JE, Bemelman WA, Oldenburg B, Marinelli AW, Lutke Holzik MF, Grubben MJ, et al. Colonic stenting versus emergency surgery for acute left-sided malignant colonic obstruction: a multicentre randomised trial. Lancet Oncol 2011;12:344-52.

17. Alcántara M, Serra-Aracil X, Falcó J, Mora L, Bombardó J, Navarro S. Prospective, controlled, randomized study of intraoperative colonic lavage versus stent placement in obstructive left-sided colonic cancer. World J Surg 2011;35:1904-10.

18. Öistämö E, Hjern F, Blomqvist L, Falkén Y, Pekkari K, AbrahamNordling M. Emergency management with resection versus proximal stoma or stent treatment and planned resection in malignant left-sided colon obstruction. World J Surg Oncol 2016;14: 232.

19. NHS Digital. National Bowel Cancer Audit Report - 2016 [Internet]. Leeds (UK): NHS Digital; 2018 [cited 2018 Jul 7]. Available from: http://content.digital.nhs.uk/catalogue/PUB22797/nati-clinaudi-bowe-canc-2016-rep-v2.pdf.

20. Shwaartz C, Fields AC, Prigoff JG, Aalberg JJ, Divino CM. Should patients with obstructing colorectal cancer have proximal diversion? Am J Surg 2017;213:742-7.

21. Pisano M, Zorcolo L, Merli C, Cimbanassi S, Poiasina E, Ceresoli M, et al. 2017 WSES guidelines on colon and rectal cancer emergencies: obstruction and perforation. World J Emerg Surg 2018; 13:36.

22. Chand M, De’Ath HD, Rasheed S, Mehta C, Bromilow J, Qureshi T. The influence of peri-operative factors for accelerated discharge following laparoscopic colorectal surgery when combined with an enhanced recovery after surgery (ERAS) pathway. Int J Surg 2016; 25:59-63.

23. Teixeira F, Akaishi EH, Ushinohama AZ, Dutra TC, Netto SD, 
Utiyama EM, et al. Can we respect the principles of oncologic resection in an emergency surgery to treat colon cancer? World J Emerg Surg 2015;10:5.

24. Tebala GD, Keane S, Osman A, Ip M, Khan AQ, Perrone L. Early discharge after colorectal resection: the positive impact of an enhanced recovery program on a rural colorectal surgery service. Surg Laparosc Endosc Percutan Tech 2016;26:e137-44.

25. Chand M, Siddiqui MR, Gupta A, Rasheed S, Tekkis P, Parvaiz A, et al. Systematic review of emergent laparoscopic colorectal surgery for benign and malignant disease. World J Gastroenterol
2014;20:16956-63.

26. Di Saverio S, Birindelli A, Mandrioli M, Podda M, Binda GA. Intracorporeal anastomoses in emergency laparoscopic colorectal surgery from a series of 59 cases: where and how to do it - a technical note and video. Colorectal Dis 2017;19:0103-7.

27. National Institute for Clinical Excellence. Improving outcomes in colorectal cancers. Manual update [Internet]. London: National Institute for Clinical Excellence; 2004 [2017 Aug 17]. Available from: https://www.nice.org.uk/guidance/csg5/resources/improving-outcomes-in-colorectal-cancer-update-pdf-773376301. 